\title{
SUPPORTING ENGINEERING STUdENT LEADERS TO INFLUENCE Organizational Culture Through a Co-Curricular LEADERSHIP PROGRAM
}

\author{
Jordan Daniow and Mike Klassen \\ Institute for Leadership Education in Engineering \\ University of Toronto \\ jordan.daniow@utoronto.ca, mike.klassen@utoronto.ca
}

\begin{abstract}
Engineering students develop leadership skills and identity through campus activities such as student government, clubs and design teams. We developed a program to enhance experiential learning of student club leaders related to organizational leadership. In this paper, we examine elements of this program related to the topic of organizational culture, a concept that has received little attention in engineering education. Students reported making use of program learning to implement and influence impactful structural and process changes in their organizations. This paper reports on the results of this teaching approach with hopes of informing and inspiring other leadership programs that aim to leverage the rich learning environment that student clubs provide.
\end{abstract}

Keywords: Organizational culture, engineering leadership, student organizations, co-curricular programs, design teams

\section{INTRODUCTION \& LITERATURE REVIEW}

Engineering programs in Canada are home to vibrant ecosystems of student organizations, and yet very few have developed targeted leadership programs that support and challenge students to grow their organizational leadership capacity. Formal leadership learning aside, student clubs and organizations have been shown to be a prevalent component of the engineering education experience. A recent study found that $87 \%$ of engineering students were involved in student organizations and other co-curricular and extra-curricular activities, including work and family activities at some point in their studies [1]. The same study showed that these activities had significant impact on the development of students' engineering and leadership skills and identity. An even more recent study published in the Journal of Engineering Education used a large multi-institutional survey dataset and found similar links between co-curricular activities and leadership skill development among engineering students [2].

Organizational culture as defined by Schein is: "The essence of group identity: Shared patterns of thought, belief, feelings, and values that result from shared experience and common learning" [3, p. 87] It is a widely accepted concept within the business and professional worlds, with many culture change programs and interventions being implemented in different contexts [3][5]. The environment and culture within any organization is a central influence on the productivity of the organization and to the quality of the experience for those who are engaged in it [3]. This same concept can be applied to student organizations whose main objective usually involves a considerable and explicit component of student learning and development. Based on decades of immersive field research, Schein argued that founders and leaders have an enormous impact on the culture of the organizations [3]. Through their conscious and unconscious mindsets, actions, and behaviours, leaders play a major role in shaping the underlying assumptions, and espoused values and beliefs that are the foundation of an organization's culture. Given that a full set of new leaders are put in place every year for most student clubs, and that there is rapid turnover due to the student cycle, leaders in student organizations are constantly in a position to have significant influence on culture. Student clubs are often starting from scratch every year without past leaders and members present to pass on cultural elements and norms. This is exacerbated by poor or nonexistent leadership transition processes in student organizations, very poor knowledge and process capture and management, and lack of any physical space or infrastructure for many clubs. This all contributes to the poor institutional memory necessary to maintain culture.

Given the importance of culture in organizations, and student leaders' special position and context to be able to influence culture, we developed a program to support student growth by building their capacity to reflect, 
observe, conceptualize and experiment with organisational leadership concepts including organizational culture. We believed that supporting leaders of student organizations to understand and apply theories of organizational culture to their clubs could lead to positive change in their organizations, and therefore an improved student experience for the wider group of members.

This paper explains some of our teaching practices in this context with hopes of informing and inspiring other leadership programs to work in innovative ways with this population of engineering students. Based on the feedback from students about the relevance of program's organizational culture elements to their learning, we are documenting those elements to enable other engineering programs to adopt aspects that fit their context. By connecting some of the program's pedagogy and content to the wider literature, this also makes a contribution to the small but growing research base on engineering leadership education in Canada.

\section{PROGRAM DESIGN}

The Summer Fellowship program was developed at the University of Toronto by the Institute for Leadership Education in Engineering. In its first year, 2015-2016, 10 student leaders participated. The target participants for this program were engineering students who were already in positions of leadership in student organizations. Students were chosen based on written application questions and a brief interview process.

An underpinning philosophy of the program was to support the personal development of these student leaders through a close, intimate community that would learn together experientially and cognitively about organizational leadership, with a particular emphasis on organizational culture. Each student proposed a personal 'change project' embedded in their organization that they planned to execute independent of this program, and were given exercises, tools and supports to make headway on that throughout the summer. The program culminated in a series of presentations that summarized progress made and lessons learned by the participants.

Over the course of eight sessions spread across 16 weeks during the summer, each session four hours in length covering 1 or 2 different topics, the students learned organizational leadership concepts and developed skills and personal awareness through experiential workshops, assignments, activities, and discussions. Organizational culture as a topic covered approximately one third of the time and focus of the program with several other frameworks, approaches, and concepts also introduced throughout the summer.
Learning about organizational culture was built into the program in three distinct ways. First, we facilitated an explicit process for the group to decide on the culture they wanted to create for Fellowship itself throughout the summer. This included a list of behaviours that would be necessary to create that culture from a blank slate at the very start of the program. This exercise held a dual purpose of role-modelling the process of facilitating a conversation about culture in a group, while also providing a concrete experience of deliberately trying to create and influence the culture of a group. At two later stages in the program, we revisited the list of behaviours to see how the culture of the group was evolving and how successful students were at creating the desired culture they had initially articulated.

Next, formal frameworks and definitions for organizational culture [3], [6] were introduced in two separate 2 hour workshops. In the first workshop, culture was defined and explained using Schein's model [3], and students were asked to reflect on the current culture of their own organization, from visible artefacts to espoused values to fundamental assumptions, thus applying the model to their own context. Students were also introduced to a cultural typology framework called the Competing Values Framework [6]. This framework presents flexibility vs. control, and internal maintenance vs. external positioning as two sets of competing cultural values that organisations balance and whose extremes create four culture types: Clan, Adhocracy, Market, and Hierarchy. Students were asked to position their organization as one of cultural types based on a questionnaire created by the authors of the framework, as well as their own intuition. They then had to reflect upon the current and ideal position of their organization within the framework. In the second workshop several weeks later, we introduced Schein's concepts of how leaders shape and embed culture in their organizations [3]. Students looked more closely at their own habits, tendencies and values and how those might be influencing their peers and the norms and unspoken expectations within the group.

Finally, students were given an assignment to visit each other's organizations by attending a meeting or event in what was called a Cultural Exchange experiment. They were asked to observe from an outside perspective the organization and the behavior of their 'host' fellow and apply the learnt theories to what they saw. They were then supposed to reflect upon and discuss the elements of culture they observed and share findings and key observations with the entire Fellowship group at the next bi-weekly session. Because of logistical challenges with scheduling the visits, only one pair of fellows managed to 
complete this assignment. This aspect will be redesigned for the next offering of the program.

\section{STUDENT RESPONSE AND LEARNING- PRELIMINARY FINDINGS}

Given this was the first cohort of the program, we placed significant focus on gathering feedback and selfreported results from program participants to inform future iterations and improvements to the program. Student feedback was collected through combined quantitative and qualitative survey around the midpoint of the program, after the key modules on culture had been completed. A similar survey was administered again at the end of the program. Students were also required to make a final presentation of their own learning, the results they achieved in their own organizations, and their future plans for the year ahead. Finally, a focus group immediately post-program was conducted, as well as informal post-program interviews with individual participants 3-4 months into the school year. Interviews were focused on identifying the elements and concepts of the program that were still being utilized by students, and to see the progress and results made on implementing plans and creating changes in their organizations.

Participant feedback suggested that students appreciated the two theoretical sessions on organizational culture, but they wanted to learn even more about how to apply these theories into their club contexts - how to analyze culture, and how to embed it more effectively. The positive response to these elements of the program was further reinforced by students in their final presentations where a majority of them explicitly reported their key learning to be around culture. Approximately half of the students also articulated their main goal using the culture framing and language. A few students also reported that some of their key learnings were as a result of the open and collaborative culture that had been explicitly developed with Fellowship cohort itself.

In final presentations for the program, a vast majority of students reported one or more of the following changes resulting from the program: a personal behaviour change, an organisational process or structure change, or an actual positive change in the culture of their organisation.

The most significant example of a change was implemented by the president of a large established multidisciplinary engineering design team on campus. The change goal of the president was to "strengthen internal sense of community and create a culture of growth, ambition, and social consciousness". In terms of organizational process change related to that goal, the president instituted bi-weekly/monthly meetings to facilitate discussion, planning and feedback with the executive team and highly engaged members around this change. These meetings were also used to encourage executives and members to be role models and champions for culture change in the organization. In follow up interviews and conversations after the program completed, it emerged that the president also created a specific Leadership Development director position in the organisation with a focus on the growth of the members and culture change interventions. There was an acknowledgement that actual culture change and the results of that culture change on the performance of the organization is very difficult to measure, so the president initiated a long-term qualitative research project to explore the results of culture change on performance to be carried out by the Leadership Development director. This research project has now been fully outlined and the Leadership Development director has applied to and been accepted into the second year of the Summer Fellowship.

Another example involved a small and new design team that had been created the same year that the Fellowship program was launched. The founder's goal entering the program was to: "create a learning organization culture within the Design Team." This student reported that through a process of developing a shared vision and goal within the organization throughout various stages of the summer, they were able to instill a sense of belonging and active learning into the organization's mandate. The desired change was also reflected in people's behavior and the performance of the group around setting and meeting timelines. This demonstrates at least a very strong seed for developing the desired culture in the organization. The student later reported in follow up interviews throughout the year that it was difficult to maintain the results and progress achieved during the summer, as pressures of the academic year mounted, and the team came up against significant challenges. Eventually, focused shifted towards instilling a culture of resilience into the organization and its members, which was supported through another tailored leadership program.

\section{DISCUSSION AND CONCLUSIONS}

The group feedback and individual cases presented give an indication that we are on the right track to achieve the intended goals of the program. The feedback forms and individual follow-up interviews tell us that students found the material stimulating and relevant, and that they continued to value it even 3 months after the program had finished. Practically, this leads us to continue to maintain this focus in our curriculum, and to look for new ways to integrate and connect the sessions on organizational culture with other topics, such as change management, power and personal reflection. We also think that rapid iteration of concept and application, from models of 
culture to practical contexts in which students work, is important to help students adopt the language and framing.

An interesting finding is that about half of the students articulated specific changes to their organizational structure (combining sub-teams; adding/removing positions; rewriting mission statements) despite there not being any explicit instruction or material on this. This highlights an opportunity for us to add a module on organizational structure to next year's offering, and to explicitly show the conceptual links between structure and culture.

In a few cases, we can reasonably claim that participants were successful in beginning to implement cultural change in their organisations which might lead to an improved environment for other students in the organization. However, we have not done any wider evaluation of the effects of these intended changes on other members of the organizations. This was beyond the scope of our resources. A promising lead to follow-up on is the internal research project of the multidisciplinary design team, which we are supporting from a research design perspective.

Our findings are limited in a few important ways. All data was self-reported by the participants, and they were likely motivated to prove to their peers and program facilitators that they had successfully applied the concepts and achieved at least some results in their organisations. Also, while we did gather from multiple sources, they were not designed with a coherent evaluation framework in mind. We are working to address this shortcoming though an explicit program evaluation process involving the development a logic model and theory of change for the program. We will use this model to guide the evaluation of clearly structured program outcomes and impacts for use with the second iteration of the program.
This program acts as a reasonable case study in using a co-curricular experiential learning program to leverage highly engaged students to improve the overall student environment and leadership learning in an engineering faculty. Students in the program were able to conceptually grasp multiple models of organizational culture and see how they explained behaviours and dynamics in their own organizations. A few were able to use this to inform intentional changes to their organizational structure. The program is now being launched in its second iteration, with a slightly larger cohort.

\section{References}

[1] C. Rottmann, R. Sacks, M. Klassen, and D. Reeve, "Sports, arts and concrete canoes: Engineers learning to lead outside the for-mal curriculum," presented at the 2016 ASEE Annual Conference \& Exposition, New Orleans, LA, 2016.

[2] D. B. Knight and B. J. Novoselich, "Curricular and Cocurricular Influences on Undergraduate Engineering Student Leadership,” J. Eng. Educ., vol. 106, no. 1, pp. 4470, Jan. 2017.

[3] E. H. Schein, Organizational culture and leadership, vol. 2. John Wiley \& Sons, 2010.

[4] W. G. Tierney, "Organizational Culture in Higher Education," The Journal of Higher Education, vol. 59, no. 1, pp. 2-21, Jan. 1988.

[5] K. E. Weick and R. E. Quinn, "Organizational change and development," Annual review of psychology, vol. 50, no. 1, pp. 361-386, 1999.

[6] K. S. Cameron and R. E. Quinn, Diagnosing and changing organizational culture: Based on the competing values framework. John Wiley \& Sons, 2005. 